\title{
Large Frontoethmoidal Mucocele: Treatment and Review
}

\author{
Manish Gupta, Bhushan Chauhan, Monika Gupta
}

\begin{abstract}
Paranasal sinus mucoceles are slowly expanding cystic lesions leading to sinus expansion, bony erosion and ultimately extension into the orbit and cranial cavity. Mucoceles account for 4 to $8.5 \%$ of expanding orbital lesions, with frontal and ethmoidal sinuses as the most common sites. We describe a large frontoethmoidal mucocele that presented with diplopia, headache and displacement of globe and was successfully managed by endoscopic sinus surgery.
\end{abstract}

Keywords: Frontoethmoidal mucocele, Endoscopic sinus surgery.

How to cite this article: Gupta M, Chauhan B, Gupta M. Large Frontoethmoidal Mucocele: Treatment and Review. Clin Rhinol An Int J 2013;6(3):126-128.

Source of support: Nil

Conflict of interest: None declared

\section{INTRODUCTION}

A mucocele is a chronic, cystic lesion of the paranasal sinuses containing sterile mucoid secretions, which is lined with pseudostratified or low-columnar epithelium containing occasional goblet cells. ${ }^{1}$ This lesion expands slowly with pressure and inflammation causing cytokine release from lymphocytes and monocytes, which in turn stimulates fibroblasts to secrete prostaglandins and collagenases causing bone resorption, ${ }^{2}$ and frequently requires 10 years or more to become symptomatic ${ }^{3}$ when they extend into the orbit or cranial cavity.

Men and women are affected equally, and these lesions are mostly encountered during the third and fourth decades of life.

We describe a large Frontoethmoidal mucocele that presented with diplopia, headache and displacement of globe and was successfully managed by endoscopic sinus surgery.

\section{CASE REPORT}

A 26-year-old female presented with a 2 years history of left sided headache, especially at her forehead and eye. She also complained of left side forehead swelling for 7 months. The swelling was gradual in onset and progressive since then. She gave a history of nasal operation at another center for apparent chronic sinusitis via endonasal/external route 5 years back. Details of earlier operation and investigations were not available.

On examination patient had $4 \times 3 \mathrm{~cm}$ swelling over left frontal region and medial canthus pushing left globe downward, outward and laterally (Fig. 1). There was
$2 \mathrm{~cm}$ linear scar in nasofacial crease just medial to medial canthus. There was mild tenderness over the left frontal bone and overlying skin was free. Diagnostic nasal endoscopy performed under local anesthesia revealed large septal perforation with left ethmoidal area bulge and frontal recess obliterated. Eye examination revealed mild left proptosis with restricted movement of eyeball in upward and medial direction and loss of vision (6/36 on Snellen's chart). Fundus examination revealed left disk edema.

Computerized tomogram nose and paranasal sinuses showed a large well defined soft tissue density mass measuring $46 \times 37 \times 35 \mathrm{~mm}$ showing attenuation values of 32 to $35 \mathrm{HU}$ in left ethmoid and left frontal sinus (Figs 2 and 3 ). The expansion of left frontal and anterior ethmoidal sinus was extending into extraconal space of left orbit, with erosion of bony wall (lamina papyracea) at places. Mass effect was appreciated on left medial rectus and superior rectus muscles and left globe was displaced laterally and inferiorly, which otherwise was normal. No obvious extension of mass was seen intracranially and no significant enhancement seen on postcontrast images.

An endoscopic sinus surgery was performed under local anesthesia, soft tissue in front of the frontal recess was excised and the thick discolored mucus was aspirated. Intraoperatively proptosis disappeared immediately (Fig. 4) and postoperatively there was prompt resolution of diplopia, vision loss and disk edema. The septal perforation was asymptomatic and thus not operated upon. The culture sensitivity test for the aspirated mucus showed no growth after 48 hours. There was no complication perioperatively.

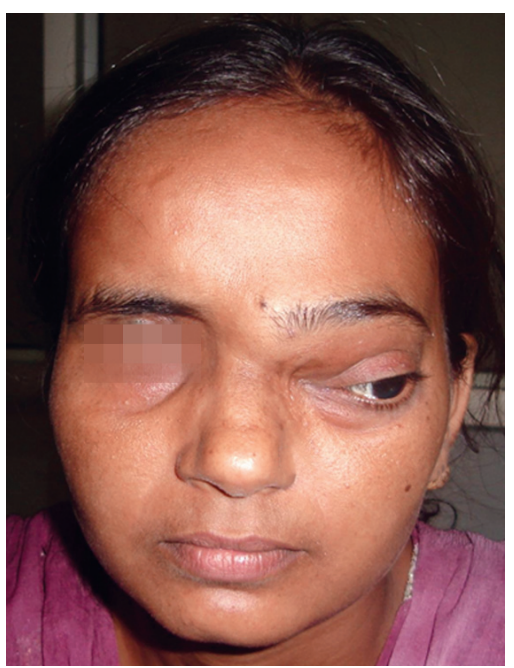

Fig. 1: Clinical photograph showing left frontal swelling, pushing left globe downward, outward and laterally 


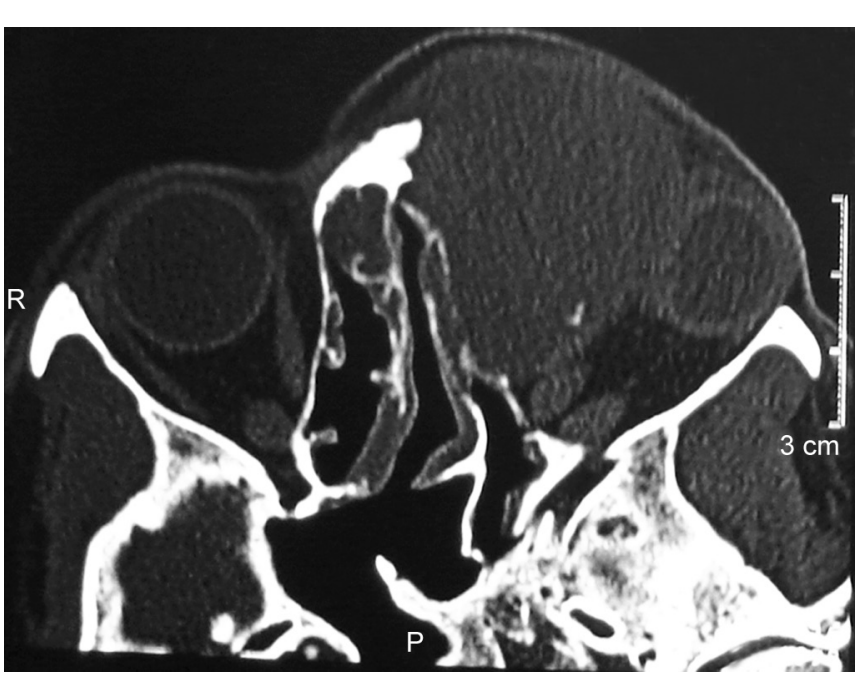

Fig. 2: Axial section computed tomogram showing large soft tissue density swelling in left frontal and ethmoid area with bony expansion

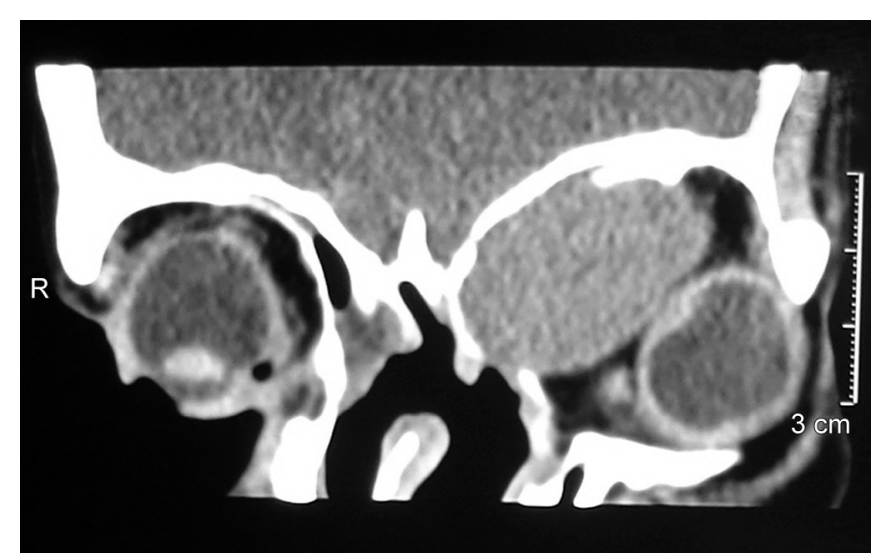

Fig. 3: Coronal section computed tomogram showing same swelling in the superior-medial quadrant of orbit with evident septal perforation

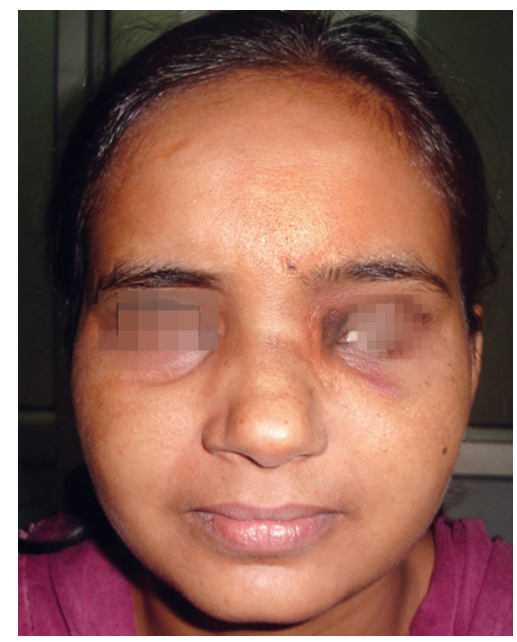

Fig. 4: Postoperative clinical picture showing complete resolution of swelling

The patient was discharged 2 days postoperatively following pack removal.

The 6 months follow-up endoscopy showed wide draining frontal recess with no recurrence.

\section{DISCUSSION}

Regarding the etiology of mucocele, some suggest they develop from obstruction of the duct of a minor salivary gland located within the lining of the paranasal sinus, whereas others believe that mucocele formation occurs when there is obstruction of the sinus ostium. Either mechanism may result in mucocele formation. Thus, histologically mucocele may be primary or secondary. Primary are mucous retention cysts while secondary lined by pseudostratified columnar epithelium and formed due to obstructed sinus ostium are true mucocele. ${ }^{4}$ Obstruction of the sinus due to previous surgery or trauma also may lead to mucocele formation as in our case.

The diagnosis of mucocele is based on the history, physical examination, and radiological findings. Plain sinus X-rays of a frontoethmoidal mucocele shows the classical expanded frontal sinus with loss of scalloped margins and translucence and depression or erosion of supraorbital ridge. CT and magnetic resonance imaging (MRI) are effective in detecting the lesion and in demonstrating any intracranial extension. ${ }^{5} \mathrm{CT}$ is the preferred imaging modality as it clearly shows the expanded, airless sinus filled with homogeneous material. The walls of the involved sinus may be thickened due to sclerosis or thinned and eroded at places. The difference between a mucocele and mucous retention cyst can be made by the presence of air outlining the upper surface of retention cyst. ${ }^{6}$

A clinically significant mucocele most commonly originates in the frontal sinus. ${ }^{5}$ The findings and symptoms associated with a mucocele depend on its location and on the extent of bony erosion. Complications arise as a result of infection or expansion of mucocele. Untreated mucocele can get infected (mucopyocele) and infection spreading around may cause cellulitis in soft tissue, osteomyelitis and septicemia. The lesion may extend to the orbital and intracranial structures and lead to meningitis, brain abscess or cerebrospinal fluid (CSF) fistulas. ${ }^{3}$ The main symptoms of orbital involvement are pain, swelling, eye ball protrusion, double vision and loss of vision. Proptosis is usually the chief complaint and oculomotor nerve palsy is rare. ${ }^{7}$ Displacement of the globe is in a downward and outward direction ${ }^{8}$ and this leads to diplopia. Sometimes, due to bony expansion and thinning of the overlying bone, the characteristic 'egg shell' cracking sensation may be felt over the swelling.

The choice of the operative procedure for treatment of paranasal sinus mucocele depends on the degree of extension. ${ }^{9}$ Surgery is the only effective treatment and may range from functional endoscopic sinus surgery to craniotomy and craniofacial exposure with or without obliteration of the sinus. ${ }^{10}$ Though, some recommend 
intranasal approach to be of first choice, even in patients with intracranial extension, as it is less invasive ${ }^{9}$ and of the possibility that the lesion can be diagnosed and completely removed without the need of craniotomy. ${ }^{11}$

The transcranial approach is an extensive procedure involving an external incision, periosteal elevation, and fracturing of sinus floor in creation of the flaps. It also has a significant morbidity as stripping of the mucocele lining occasionally leads to dural injury and CSF leaks. ${ }^{12}$ The follow-up of an obliterated sinus can also be unreliable as imaging may not be able to distinguish an obliterated sinus from a recurrent mucocele, ${ }^{8}$ moreover if the mucosa is left behind and the sinus obliterated, a recurrence is highly likely. ${ }^{12}$

The intranasal drainage and marsupialization of mucocele using endoscopes may be considered as the procedure of choice for treatment of paranasal sinus mucocele with orbital extension and a direct orbital approach is rarely necessary. ${ }^{8}$ This conservative surgery involving marsupialization of the mucocele and widening the sinus drainage is based on the principle that the etiological factor is blocked ostial drainage rather than diseased mucous membrane, and this not only relieves the symptoms of the mucocele but also prevents reaccumulation of the mucus later. ${ }^{13}$

\section{REFERENCES}

1. Stiernberg CM, Bailey BI, Calhoun KH. Quinn FB. Management of invasive frontoethmoidal sinus mucoceles. Arch Otolaryngol Head Neck Surg 1986;112:1060-1063.

2. Lund VJ. Frontoethmoidal mucoceles: a histopathological analysis. J Laryngol Otol 1991;105:921-923.

3. Galie M, Mandriali S, Tieghi R, Clauser L. Giant mucocele of the frontal sinus. J Craniofac Surg 2005;16:933-935.

4. Marks SC, Latoni JD, Mathog RH. Mucoceles of the maxillary sinus. Otolaryngol Head Neck Surg 1997;117:18-21.

5. CansizH, Yener M, Giiveny MG, Canbaz B. Giant frontoethmoidal mucocele with intracranial extension: case report. Ear Nose Throat J 2003;82:50-52.
6. Som PM, Curtin HD. Head and Neck imaging. Mosby 4th ed. 1:204-230,838-840.

7. Lin CJ, Kaa CH, Kang BH, Wang HW. Frontal sinus presenting as oculomotor nerve palsy. Otolaryngol Head Neck Surg 2002; 126:588-590.

8. Khong JJ, Malhotra R, Wormald PJ, Selva D. Endoscopic sinus surgery for paranasal sinus mucocele with orbital involvement. Eye 2004; 18:877-881.

9. Koike Y, Takara K, Chiba Y, Suzuki SI, Mlirai M, Ita H. Intracranial extension of paranasal sinus mucocele: two case reports. Surg Neurol 1996;45:44-48.

10. Weitzel EK, Hollier LH, Calzada G,. Manalidis S. Single stage management of complex fronto-orbital mucocele. J Craniofac Surg 2002;13:739-745.

11. Delfini R, Missari P, Lannetti G, Ciappetta P, Cantare G. Mucoceles of the paranasal sinuses with intracranial and intraorbital extension: report of 28 cases. Neurosurgery 1993: 32:901-906.

12. Har-EL G. Endoscopic management of 108 sinus mucoceles. Laryngoscope 2001;111:2131-2134.

13. Har-El G, Balwally AN, Lucente FE. Sinus mucoceles: Is marsupialization enough? Otolaryngol Head Neck Surg 1997;117:633-640

\section{ABOUT THE AUTHORS}

\section{Manish Gupta}

Associate Professor, Department of ENT, Gian Sagar Medical College and Hospital, Patiala, Punjab, India

Correspondence Address: 1156-C, Government Medical College and Hospital Campus, Sector 32 B, Chandigarh, India, Phone: 9915025819 e-mail: manishgupta1217@gmail.com

\section{Bhushan Chauhan}

Assistant Professor, Department of Otolaryngology, Gian Sagar Medical College and Hospital, Patiala, Punjab, India

\section{Monika Gupta}

Associate Professor, Department of Medicine, Gian Sagar Medical College and Hospital, Patiala, Punjab, India 